\title{
Comparison of Three Solar Cells Based on DSSC, Perovskite and Polymer Structures
}

\author{
Melika Dolatdoost, Farhad A. Boroumand \\ Organic Electronics Laboratory, Electrical Engineering Faculty, K. N. Toosi University of Technology \\ Seyed Khandan Bridge, Shariati Ave. Tehran, Iran \\ melika.dolatdoost@gmail.com; boroumand@kntu.ac.ir
}

\section{Extended Abstract}

In this work, we compare three solar cell structures that have been captured the attention of scientists as future technologies for green energy production. Dye synthesized solar cell was fabricated on FTO anode substrate using N719 dye active layer and platinum cathode based on Dr. Blade technique [1].

Perovskite solar cell was also made on uniform FTO on Glass as positive electrode. Mesoporous titania was deposited with Spin-Dip method and then, $\mathrm{PbI}_{2}$ was deposited and the whole sample placed in $\mathrm{CH}_{3} \mathrm{NH}_{3} \mathrm{I}$ and Spiro-OMeTAD was added to the solution. The structure was completed with depositing Gold as cathode of Perovskite cell [2]. For polymer based solar cell ITO on PET was considered as anode contact with MEH-PPV:ZnO nanocomposite polymer as active layer and Aluminum as negative electrode [3].

Perovskite structure had its own features such as high absorption coefficient, deep diffusion length of carriers and slow recombination speed. Also existence of Spiro-OMeTAD material reduced the recombination of charges, resulting in highest efficiency of $8.7 \%$ among three devices and the utmost $I_{\mathrm{sc}}$ of $19.98 \mathrm{~mA} / \mathrm{cm}^{2} . \mathrm{V}_{\mathrm{oc}}$ for this cell was acquired as $0.874 \mathrm{~V}$. DSSC cell with N719 had high absorption in Infra-Red region of spectrum near 900nm. This device showed an efficiency of $6.1 \%$ with $\mathrm{I}_{\mathrm{sc}}$ of $14.94 \mathrm{~mA} / \mathrm{cm}^{2}$ and $\mathrm{V}_{\mathrm{oc}}$ of $0.7 \mathrm{~V}$. Polymer solar cell exhibited the worse performance among the devices with efficiency of $0.74 \%, \mathrm{I}_{\mathrm{sc}}$ of $5.12 \mathrm{~mA} / \mathrm{cm}^{2}$ and $\mathrm{V}_{\text {oc }}$ of $0.349 \mathrm{~V}$.

In two cells of Perovskite and Dye synthesized solar cells, due to the use of FTO, there is less moisture absorption, which increases the efficiency of these two types of cells compared to the Polymer cell. The use of costly and rare materials, such as Spiro-OMeTAD in Perovskite cells, has made it more expensive than two other types.

From the fabrication point of view, polymer structure had the easiest and bottommost cost of process, since spin coating was mostly used. Perovskite had the highest cost of fabrication because Spiro-OMeTAD was expensive. On the hand, DSSC solar cell had the advantage of low cost to performance ratio.

\section{References}

[1] H. Imahori, T. Umeyama, S. Seigo Ito, "Large $\pi$-Aromatic Molecules as Potential Sensitizers for Highly Efficient Dye-Sensitized Solar Cells,” Acc. Chem. Res., vol. 42, no. 11, pp. 1809-1818, 2009.

[2] J. Hyuck Heo, S. Hyuk Im, J. H. Noh, T. N. Mandal, C. Lim, J. Ah Chang, Y. H. Lee, H. Kim, A. Sarkar, M. K. Nazeeruddin, M. Gratzel, S. I. Seok, "Efficient Inorganic-Organic Hybrid Heterojunction Solar Cells Containing Perovskite Compound and Polymeric Hole Conductors," Nature Photonics, vol. 7, pp. 486-491, 2013.

[3] D. Bi, F. Wu, W. Yue, Q. Qu, Q. Cui, Z. Qiu, C. Liu, W. Shen, M. Wang, "Improved Performance Of Meh-Ppv/Zno Solar Cells by Addition of Lithium Salt," Solar Energy, vol. 85, no. 11, pp. 2819-2825, 2011. 